\title{
Anal Ectopic Fibroadenoma
}

National Cancer Institute

\section{Source}

National Cancer Institute. Anal Ectopic Fibroadenoma. NCI Thesaurus. Code C139546.

A benign epithelial-stromal neoplasm that arises from the anus and resembles the breast fibroadenoma. 